\title{
Research on Regional Cultural Characteristics in the Design of Electric Vehicle Charging Pile
}

\author{
Chunli Liu * \\ School of Mechanical-electronic and Vehicle Engineering \\ Weifang University \\ Weifang, Shandong, China \\ wfumay@163.com
}

\begin{abstract}
Regional culture is an important feature of urban public facilities. It provides the political, economic, and cultural backgrounds of public facilities. The climate characteristics and cultural customs of different regions are not the same, and the demand for urban public facilities is different. If public facilities are separated from regional culture, they will lose their individuality. This paper discusses from five dimensions: historical and cultural dimension, natural dimension, ecological dimension, artistic characteristic dimension and Function dimension order to discuss the new idea of electric vehicle charging pile design under the influence of regional culture.
\end{abstract}

Keywords-Charging pile appearance; Public facilities; Weifang history and culture; Regional culture

\section{INTRODUCTION}

Regional culture is the combination of people's thinking patterns and behavior patterns in a certain time and space, and gradually formed through long-term deposition, including material level, institutional level, and conceptual level, mainly in material culture and non-material culture. Each city has its own unique tradition and characteristic culture. It is the accumulation of history and the crystallization of people's creation. It is also a valuable asset for us to carry out design innovation today. Public facilities are urban environmental products that integrate environmental design and product design developed along with the development of the city. It has the cultural function of embodying urban cultural characteristics and continuing the tradition of people's life ${ }^{[1]}$.

With the development of new energy vehicle industry in the world, all countries are vigorously developing energy conservation and emission reduction to enhance environmental protection. Our country also attaches great importance to the development of electric vehicles, and has promulgated a series of policies and regulations to support and standardize the development of electric vehicles. "Guidelines for the development of electric vehicle charging infrastructure (20152020)" explicitly proposed the overall goal of the development of the charging infrastructure during the "13th Five-Year" period, and the construction objectives and road map in the sub region and the division. It is expected that in 2020, a centralized replacement power station will be built in 12 thousand and 4 million 800 thousand dispersed charging pile will be built. It can meet the charging demand of 5 million electric vehicles ${ }^{[2]}$.The charging pile will become an indispensable part of the urban public facilities and will play a more and more important role in the daily life of people and in the development of the city. Therefore, combined with modern technology, the city's geographical characteristics, traditional customs, humanities and other characteristics of the cultural material into a specific form of facilities, regional culture to participate in the design of urban facilities, not only inherit the regional characteristics of the culture and make it more popular, popular, but also is beneficial to design new public facilities suitable for the lifestyles and customs of local people, and enrich the cultural connotation of public facilities. This paper aims to analyze the influence and function of the design of Weifang historical culture into the charging pile.

\section{II. "Thousand City SidE" AND "Cultural Amnesia"}

With the gradual acceleration of the urbanization process, the city that should have a unique style and characteristics after the time accumulation, but it grows like a format and presents a high degree of assimilation ${ }^{[3]}$. This "Thousand City Side" disaster is killing the soul of the city. In the design of public facilities, due to the lack of influence and guidance of urban regional culture, the design concept is single and the design principle is universally applicable in ecology, environmental protection, and aesthetics. As a result, designers and ordinary citizens have to face the same urban public facilities every day. Fragmented cultural memories have separated people from space. In the face of such problems, there is an urgent need to increase research on the cultural characteristics of urban areas in the field of public infrastructure design. Excavate the richness and complexity of culture, what kind of cultural tradition should project what kind of design appearance, improve the spiritual value of public facilities. At the level of cultural inheritance, we find a balance between inheritance and innovation, deepen and expand on the basis of traditional theory, and find the blending point from the deeper cultural aesthetics $^{[4]}$.

\section{LACK OF TRADITIONAL METHODS}

The essence of traditional culture in the city is not only reflected as a design trend, but also as the crystallization of Oriental wisdom. In the aspect of public facilities design, design is not only a traditional symbol or a traditional craft full of meanings, but also should be reflected in the aspects of lifestyle, living habits, life philosophy, social etiquette and emotion ${ }^{[5]}$.The emergence of various styles and schools of western design originates from the process of western reform 
and the comprehensive consideration of politics, economy and life. The design that only USES the western design concept but does not take root in the traditional Chinese techniques means to use the western philosophy and life attitude to encroach on the Chinese tradition and lifestyle. Over time, design will become a water without source and a tree without roots, and a country lacking cultural ecology will gradually lose the nation's ability to self-purification and rehabilitation. The philosophical core of the harmonious beauty and the integration of man and nature advocated by ancient Confucianism provides an intelligent thinking Angle for contemporary design. The tradition should be fully considered in the design, but the tradition is not static, but created and evolved in various social interactions ${ }^{[6]}$.

\section{WeIFAng History AND CUlture}

Weifang, also known as the "kite capital", is located in the central part of the Shandong peninsula. Weifang has become an important hub of the ancient Jingdong since the Qin Dynasty. From the end of the Qing Dynasty to the early period of the Republic of China, it was the most developed period in Weifang handicraft industry. The handicraft industry of Wei embroidery, silver, nuclear carving, antique copper products and toys and other family handicraft industries were numerous. It was famous for 'two hundred red furnaces, three thousand bronze blacksmith, nine thousand embroidery machine, one hundred thousand loom". It is a famous handicraft city in history. In the Qing Dynasty, there were "South Suzhou and North Wei county". In 1904, under the proposal of the German colonists, Weifang opened its ports.

The colorful folk activities and folk art constitute the characteristics of weifang culture. Weifang folk art is rich in variety, unique in style and exquisite in art. It carries profound cultural connotation and can be regarded as the local treasure in the treasure-house of Chinese national art. Weifang kites, for example, are popular in Ming dynasty, qing dynasty, and modern times. Since 1984, weifang municipal government has carried forward this outstanding folk culture tradition and held an international kite meeting in weifang city at the beginning of April every year. After 34 years of continuous efforts, weifang has become an international center of kite culture communication and exchange. For another example, yangjiabu woodblock New Year painting has a history of more than 400 years. It is one of the three famous folk New Year paintings in China. For example, see Fig. 1.
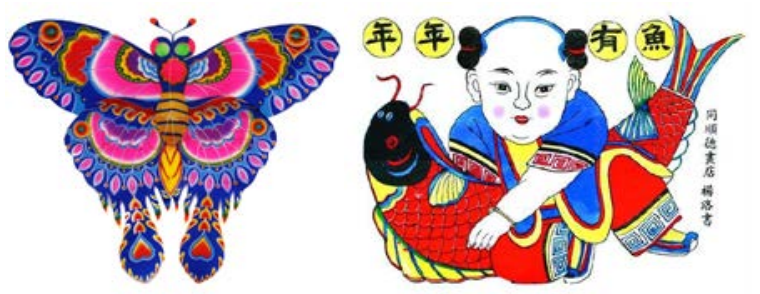

Fig. 1. Weifang kites and New Year paintings.
V. CONCLUSION APPLICATION OF REGIONAL CULTURAL ELEMENTS IN THE DESIGN OF ELECTRIC VEHICLE CHARGING PILES

The design method is the spirit, the form should be born with the spirit, and the excellent public facilities design is the art that carries the culture and the mainstream values of the times. Therefore, the electric vehicle charging pile should be thought and molded from 4 aspects of historical and cultural dimension, natural dimension, ecological latitude and artistic feature dimension.

\section{A. Historical and Cultural Dimensions}

There is an ancient Chinese saying, "The unique features of a local environment always give special characteristics to its inhabitants" the city's style and features show Different levels of performance because of the differences in urban culture. Therefore, the appearance of different cities, such as the solemn atmosphere of Beijing, the pluralistic and inclusive Shanghai, the delicate Hangzhou and so on, has been formed. The historical context of every city cannot be copied. In the process of design, public facilities must respect history and put it under the cultural background of the city, excavate the characteristics that coincide with the city's character, and start with the unique cultural elements of the local people's deep emotion and excavate the inspiration from the region. Such as relics, cultural relics, paintings, literature legends, folk songs and other historical elements, through the design and construction of the collective memory of public facilities users, metaphorical spirit and concept of the times, the transfer of historical and cultural and customs and people ${ }^{[7]}$.Imagine in the electric vehicles more and more popular tomorrow, weifang citizens and even other cities to weifang driving tourism friends in the charging station can understand weifang history and culture connotation and significance, the charging pile by the design of Weifang's history and culture brings a unique charm value to the general public and the whole city.

\section{B. Natural Dimensions}

Natural geographical conditions are the basic conditions for the formation of urban features ${ }^{[8]}$. There is no clear boundary between urban public facilities and nature, but it plays a role of mediation and transition. As a part of the urban environment, public facilities are not isolated from the environment. Facing trees and grass, high-rises or rivers and lakes, public facilities are placed in the cycle of changing seasons. Different regions have different characteristics of topography, landform and geographical environment. The design of charging piles for electric vehicles should be natural and appropriate to local conditions, taking into full consideration climatic factors, site relations and geomorphologic features, paying attention to people's behavior characteristics and nature in the outdoor environment, respecting nature and fully integrating it into the overall landscape of urban areas, and highlighting local characteristics.

\section{Ecological Dimensions}

With the increasing awareness of the protection of resources and environment in the world, new theories, new 
technologies and new ideas about resources protection are also being put forward and implemented. The production and consumption of any product should involve resource problems and public facilities are no exception. The design of public facilities must be committed to forming an optimized environmental system, paying attention to the ecological environment, showing the symbiosis between human beings and the environment, and realizing the balance between man and nature renewal and higher levels, which undoubtedly belongs to the reform of design concepts. Designers in material selection, production and processing, use and waste treatment facilities and so on each link, must take the sustainable development as guidance, the principle of overall consideration to save the environment and resources protection, pay attention to the environment, ecological and sustainable design concept, the pursuit of a parasitic relationship between human and nature, in the design of balance in the artificial and natural objects.

\section{Artistic Dimensions}

The foothold of public facilities design is not only the construction of urban hardware facilities, but also the development of more aesthetic, aesthetic and artistic directions ${ }^{[9]}$. The design of public facilities should reflect the most regional spirit elements and highlight the most distinctive visual aesthetic of material, annotate the characteristics of the times and give the public space a personalized art logo. Public facilities are like art to activate space, and the works of public facilities with artistic features can create a humanized and poetic space environment with the characteristics of the times, and enhance the features of the urban space. If Weifang's annual painting, kite, paper-cut and other landmark symbols into the design of the charging pile, it will be able to better promote the history and culture of Weifang, and create another more representative and more cross time business card of Weifang.

\section{E. Function Dimensions}

Jacobs, a famous American city critic, believes that cities are "intricate and diverse in use ${ }^{\text {r10 }}$. The activities of people in cities usually revolve around four functions: living, working, transportation and recreation. With the gradual deepening of urban functions, the design of public facilities also generates functional differences in different regions along with the subdivision of urban functions. Under the leadership of regional functions, there is a huge difference between the applicable population of public facilities and the private attribute level of facilities themselves. Therefore, the design of charging piles should also be based on the specific land use attributes such as residential area and business district. The design of charging piles in residential areas should reflect the outdoor function of indoor function and the public function of private function more. The space of residential areas is arranged as if the outdoor living room is as warm as home. Therefore, the life of citizens becomes warm and cozy, which fully embodies the city's concern for people. The design of charging piles in the business district needs to fully consider the interaction between people and the demand for rest, and integrate the interpersonal context to meet the interpersonal cohesion. Only by fully considering the various functions can we create an applicable and humane space. Only with the participation of people, the facilities can have their dynamic spirituality and value.

\section{CONCLUSION}

The regional feature of the city is the connotation of the difference between the city and other cities and the main context of the whole urban development process. Therefore, in the design, starting from the point of regional culture, it is conducive to better grasp the key points of the design and further improve the urban environmental facilities. At the same time, it has a very important meaning for improving the height of the whole urban design. In the rapidly developing modern society, let us find the creative positioning of urban public facilities and urban natural and cultural facilities, and create a city image with urban characteristics and personality characteristics. The history and culture of Weifang city is ingeniously and accurately integrated into the appearance design of electric vehicle charging pile to inherit and develop Weifang's history and culture, which will have an important role to follow the progress of the times.

\section{REFERENCES}

[1] Li Zhuo. The Application of Regional Culture in Urban Public Facilities[D]. Changsha: Hunan Normal University, 2012

[2] WANG Xu,QI Xiang-dong.Research and design of electric car intelligent charging pile[J].Journal of Mechanical \& Electrical Engineering.2014(3):393-394

[3] Duan Jinjuan. Analysis on the Practice of Regional Culture Element in Public Facilities :Illustrated by the Case of Beijing [J]. ZHUANGSHI.2013(7): :127-128

[4] ZHOU Xinhai, CAO Xing. Urban Public Facilities Design Based on the Local Culture[J]. PACKAGING ENGINEERING.2017(2):206-207

[5] HU Tianjun, JING Jing. Public Art Facilities De- sign[M].Beijing: China Building Industry Pres, 2012.

[6] [6]WU Wei.City Characteristic Research and City Planning[M]. Shanghai: Tongji University Press,2007.

[7] MARCUS Clare Cooper.FRA NCIS Carolyn.Humanity Sites: City Open Space Design Guidelines[M].Beijing: China Building Industry Press,2001.

[8] LI Wen-jia,REN Mei,KONG Xiao-yan. Study on Public Facilities Design Based on the View of Cityscape

[9] LIU Hai-ping.Introduction to Design[M].Beijing: Beijing University Press,2010.

[10] SUN Da-li, LU Jin.Regional Cultural Reconstruction of Urban Public Facilities Design[J]. PACKAGING ENGINEERING.2018(10):280-282. 